\title{
Oxygen Delivery, Oxygen Consumption, and Metabolic Acidosis during Group B Streptococcal Sepsis in Piglets
}

\author{
WILLIAM L. MEADOW, BRIAN F. RUDINSKY, ELENE STRATES, AND KARL J. KOMAR \\ Department of Pediatrics, Wyler Children's Hospital. The University of Chicago. Chicago. Illinois 60637
}

\begin{abstract}
The development of metabolic acidosis during neonatal sepsis with group B streptococci (GBS) has been attributed to progressive tissue ischemia resulting from reduced oxygen delivery $\left(\mathrm{QO}_{2}\right)$. Using an animal model of GBS disease, we attempted to test this hypothesis by comparing the development of metabolic acidosis in two groups of piglets with comparably diminished systemic $\mathrm{QO}_{2}$, one septic and one not. Eighteen anaesthetized piglets were instrumented to observe aortic pressure, cardiac output, arterial and mixed venous blood gases, oxygen content, and hemoglobin concentration. $\mathrm{QO}_{2}$, oxygen consumption, and oxygen extraction ratio were calculated. Six piglets (group 1) received continuous infusion of live GBS organisms; six piglets (group 2) received continuous infusion of phenylephrine (PE), beginning with $10-\mu \mathrm{g} / \mathrm{kg} / \mathrm{min}$ and increasing as required to match the $\mathrm{PE}$-induced reduction in $\mathrm{QO}_{2}$ to the fall observed in the group 1 (GBS) piglets at each 30 -min interval. Group 3 piglets $(n=6)$ received $0.9 \%$ saline and served as controls. No differences in either cardiac output or $\mathrm{QO}_{2}$ were noted comparing GBS and $\mathrm{PE}$ piglets at any time interval from 0 - 180 minutes. At 120, 150 , and 180 minutes, both $\mathrm{QO}_{2}$ and cardiac output were lower in GBS and PE piglets compared to controls. Despite equivalent reductions in cardiac output and $\mathrm{QO}_{2}$, only GBS piglets developed significant metabolic acidosis, while $\mathrm{pH}$ and base deficit for PE piglets did not differ from controls. Oxygen consumption did not differ significantly among the three experimental groups at any observation time. Oxygen extraction ratio did not differ comparing PE and GBS piglets at any observation time. We conclude that the reduction of $\mathrm{QO}_{2}$ effected by GBS infusion in piglets is not, in itself, sufficient to account for the development of metabolic acidosis during these experiments. (Pediatr Res 22: 509-512, 1987)
\end{abstract}

\section{Abbreviations}

GBS, group B streptococci

$\mathrm{QO}_{2}$, systemic oxygen delivery

$\mathrm{VO}_{2}$, systemic oxygen consumption

AOP, aortic blood pressure

CVP, central venous pressure

LAP, left atrial pressure

PAP, pulmonary artery pressure

$\mathrm{CO}$, cardiac output

CI, cardiac index

SVRI, systemic vascular resistance index

Received September 17, 1986; accepted June 10, 1987

Correspondence and reprint requests, William L. Meadow, M.D., Ph.D., Department of Pediatrics-Box 325, Wyler Children's Hospital, The University of Chicago, 5825 S. Maryland Avenue, Chicago, IL 60637.

Supported in part by funds from the Children's Research Foundation of Chicago and the American Lung Association.

\author{
BD, base deficit \\ $P E$, phenylephrine \\ PEEP, positive end expiratory pressure \\ PA, pulmonary artery \\ HR, heart rate \\ $\mathrm{Hb}$, hemoglobin \\ ANOVA, 3-way analysis of variance
}

We have previously described an animal model of septic shock (1-4) which resembles sepsis in human infants in many aspects $(5-10)$. Using infusion of live GBS in piglets, we have demonstrated that GBS sepsis reduces both systemic and regional blood flow, elevates pulmonary artery pressure, elevates systemic and pulmonary vascular resistance, and is associated with the progressive development of metabolic acidosis.

We $(2,4)$ and others $(11,12)$ have speculated that acidosis during neonatal GBS sepsis can been attributed to progressive tissue ischemia resulting from reduced $\mathrm{QO}_{2}$. Using our animal model of GBS disease, we attempted to test this hypothesis by comparing the development of metabolic acidosis in two groups of piglets with comparably diminished systemic $\mathrm{QO}_{2}$, one septic and one not. We report here that septic piglets in whom $\mathrm{QO}_{2}$ was reduced by GBS infusion became significantly more acidotic than non-septic piglets whose $\mathrm{QO}_{2}$ was reduced by infusion of PE.

\section{MATERIALS AND METHODS}

Surgical preparation. Eighteen piglets (1-4 wk old; mean weight $4.5 \mathrm{~kg}$ ) received ketamine intraperitoneally $(20 \mathrm{mg} / \mathrm{kg})$, were intubated endotracheally and anaesthetized with sodium pentobarbital ( $20 \mathrm{mg} / \mathrm{kg}$ initially, $2 \mathrm{mg} / \mathrm{kg} / \mathrm{h}$ subsequently). Muscle relaxation was achieved with $d$-tubocurare $(1 \mathrm{mg} / \mathrm{kg})$. In an attempt to minimize the potentially confounding effects of hypoxia or acidosis on myocardial function during sepsis, mechanical ventilation (Harvard Medical Supplies, Dover, MA) was

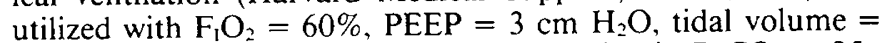
$15 \mathrm{ml} / \mathrm{kg}$ and subsequently adjusted to maintain $\mathrm{PaCO}_{2}$ at $25-$ 35 torr during the entire experiment. Warming blankets and heating lamps were used to maintain body core temperature at $37-38^{\circ} \mathrm{C}$. A suprapubic cystostomy catheter was placed to establish urinary drainage.

PE catheters providing venous access were surgically introduced into the right and left external jugular veins. Intravascular catheters attached to pressure transducers were placed in the aorta (via femoral artery), pulmonary artery (via left lateral sternotomy), and right atrium (via internal jugular vein). An external electromagnetic flow probe (Carolina Medical Electronics, King, NC) was placed around the PA, proximal to the tip of the PA catheter. During each experiment, the PA flow probe was 
zeroed frequently using the approximation that diastolic blood flow in the PA is zero. Baseline hemodynamic and metabolic observations were taken and determined stable for at least $1 \mathrm{~h}$ following the completion of surgery.

Hemodynamic monitoring. Five hemodynamic variables were measured directly and continuously: HR, phasic and mean AOP, phasic and mean PAP, phasic and mean CVP, and phasic and mean PA blood flow. In the documented absence of right to left or left to right vascular shunts, PA blood flow was taken as equivalent to total body $\mathrm{CO}$. Vascular shunts were precluded by comparison of oxygen content in blood samples obtained simultaneously from the right atrium, PA, and aorta.

From these observed variables, two additional hemodynamic variables were derived. $\mathrm{CI}$ was calculated as the ratio of $\mathrm{CO} /$ body weight. SVRI was calculated as the ratio of (AOP-CVP)/ CI.

Metabolic monitoring. Blood specimens were taken from the aorta and PA twice during the baseline stabilization period, and at 30 -min intervals thereafter until the completion of the experiment $(180 \mathrm{~min})$. From these blood samples, arterial and mixed venous values of $\mathrm{pH}, \mathrm{pO}_{2}, \mathrm{pCO}_{2}$, and $\mathrm{BD}$ were determined using a blood gas analyzer (IL 713, Instrumentation Laboratories, Lexington, MA). Additionally, arterial and mixed venous oxygen saturations $\left(\mathrm{SataO}_{2}, \mathrm{SatvO}_{2}\right)$ and oxygen contents $\left(\left[\mathrm{O}_{2}\right] \mathrm{a},\left[\mathrm{O}_{2}\right] \mathrm{v}\right)$ were determined directly from a cooximeter (IL 282, Instrumentation Laboratories) or calculated from a nomogram calibrated in our laboratory relating oxygen tension to oxygen saturation as a function of $\mathrm{pH}, \mathrm{pCO}_{2}$, and temperature of piglet blood. $\mathrm{Hb}$ content was determined by cooximeter and confirmed by measurement of serum hematocrit.

Three additional metabolic variables were derived. $\mathrm{QO}_{2}$ was calculated as $\mathrm{CI} \times\left[\mathrm{O}_{2}\right] \mathrm{a}$. $\mathrm{VO}_{2}$ was calculated as $\left(\left[\mathrm{O}_{2}\right] \mathrm{a}-\left[\mathrm{O}_{2}\right] \mathrm{v}\right)$ $\times$ CI. Oxygen extraction ratio was calculated as $\left(\left[\mathrm{O}_{2}\right] \mathrm{a}-\left[\mathrm{O}_{2}\right] \mathrm{v}\right)$ / $\left[\mathrm{O}_{2}\right] \mathrm{a}$.

Preparation of hacteria. GBS serotype $1 \mathrm{~b}$, previously isolated from an infected human newborn, was grown in $250 \mathrm{ml}$ ToddHewitt broth to late log phase $\left(\sim 3 \times 10^{9}\right.$ organisms $\left./ \mathrm{ml}\right)$. The bacteria were then centrifuged, the supernatant decanted, and the organisms resuspended to their original concentration in $0.9 \% \mathrm{NaCl}$. Quantitative cultures of the bacterial inoculum were performed by serial dilution to allow retrospective calculation of the rate of bacterial infusion.

Experimental protocol. The piglets were divided into three experimental groups (six piglets/group). Piglets in group 1 received continuous infusion of live, washed, resuspended GBS organisms, beginning at $\sim 0.5 \times 10^{7}$ organisms $/ \mathrm{kg} / \mathrm{min}$ and increasing to a maximum of $1 \times 10^{8}$ organisms $/ \mathrm{kg} / \mathrm{min}$ over 180 min. Piglets in group 2 received continuous infusion of $P E$, beginning with $10 \mu \mathrm{g} / \mathrm{kg} / \mathrm{min}$ and increasing as necessary to reduce $\mathrm{QO}_{2}$ during each 30 -min observation period to an extent comparable to the mean reduction in $\mathrm{QO}_{2}$ observed for group 1 (GBS) animals. Piglets in group 3 received continuous infusion of placebo $(0.9 \% \mathrm{NaCl})$ for $180 \mathrm{~min}$, and served as a control group for the animals receiving GBS or PE. Hemodynamic data were obtained continuously for animals in each experimental group, while metabolic observations were made twice during the baseline period and at 30-min intervals after the start of each experimental protocol for $180 \mathrm{~min}$.

Data presentation and statistical analysis. The hemodynamic and metabolic effects of GBS, PE, and placebo for piglets in groups 1,2 , and 3 , respectively, are displayed at baseline (Table 1) and as a function of time (Figs. 1-4). Statistical comparisons among the three experimental groups were determined at baseline and at each subsequent 30-minute interval using ANOVA (13). Where a significant difference among the three experimental groups was noted, pairwise comparisons were performed using Student's two-tailed $t$ test modified by the Bonferroni correction for multiple statistical analyses. Statistical comparisons of sequential observations within a single experimental group were performed using repeated-measures ANOVA with Bonferroni
Table 1 . Baseline values (mean $\pm S D, n=6$ animals/group)

\begin{tabular}{|c|c|c|c|}
\hline & $\begin{array}{c}\text { Group } 1 \\
\text { (GBS) }\end{array}$ & $\begin{array}{c}\text { Group } 2 \\
(\mathrm{PE})\end{array}$ & $\begin{array}{c}\text { Group } 3 \\
\text { (placebo) }\end{array}$ \\
\hline $\begin{array}{l}\text { ADP } \\
(\mathrm{mm} \mathrm{Hg})\end{array}$ & $\begin{array}{c}95.2 \\
(10.3)\end{array}$ & $\begin{array}{l}103.3 \\
(15.2)\end{array}$ & $\begin{array}{c}89.5 \\
(17.3)\end{array}$ \\
\hline $\begin{array}{l}\text { PAP } \\
(\mathrm{mm} \mathrm{Hg})\end{array}$ & $\begin{array}{l}13.2 \\
(3.1)\end{array}$ & $\begin{array}{l}14.0 \\
(4.2)\end{array}$ & $\begin{array}{l}13.8 \\
(5.4)\end{array}$ \\
\hline $\mathrm{Cl}$ & 118 & 103 & 115 \\
\hline$(\mathrm{ml} / \mathrm{kg} / \mathrm{min})$ & $(25)$ & $(29)$ & $(42)$ \\
\hline $\mathrm{HR}$ & 139 & 171 & 160 \\
\hline (bpm) & $(24)$ & $(28)$ & $(36)$ \\
\hline SVRI & 0.85 & 0.83 & 0.83 \\
\hline$(\mathrm{mm} \mathrm{Hg} / \mathrm{ml} / \mathrm{kg} / \mathrm{min})$ & $(.25)$ & $(.15)$ & $(.23)$ \\
\hline $\mathrm{pH}$ & 7.49 & 7.47 & 7.49 \\
\hline (U) & $(.03)$ & $(.06)$ & $(.05)$ \\
\hline $\mathrm{PaO}_{2}$ & 265 & 215 & 242 \\
\hline (torr) & (34) & $(20)$ & $(27)$ \\
\hline $\mathrm{PaCO}_{2}$ & 27 & 30 & 28 \\
\hline (torr) & $(4.1)$ & $(3.8)$ & (2.9) \\
\hline Base deficit & -0.8 & 1.6 & 0.0 \\
\hline (meq/liter) & $(2.4)$ & $(3.0)$ & $(2.7)$ \\
\hline $\mathrm{QO}_{2}$ & 14.8 & 17.9 & 17.9 \\
\hline$(\mathrm{ml} \mathrm{O} / 2 / \mathrm{kg} / \mathrm{min})$ & $(1.9)$ & $(4.4)$ & (9.9) \\
\hline $\mathrm{VO}_{2}$ & 5.8 & 7.3 & 7.6 \\
\hline$(\mathrm{ml} \mathrm{O} / 2 / \mathrm{kg} / \mathrm{min})$ & $(1.6)$ & $(2.6)$ & $(3.0)$ \\
\hline \multirow{2}{*}{$\% \mathrm{O}_{2}$ extraction } & 39 & 40 & 45 \\
\hline & $(10)$ & $(5)$ & (9) \\
\hline
\end{tabular}

correction for multiple comparisons (13). The null hypothesis was rejected at $p<0.05$.

\section{RESULTS}

Table 1 displays the hemodynamic and metabolic status of piglets in each experimental group at the end of the baseline observation period prior to experimental intervention. No significant difference in any variable was noted among the three groups.

Figure 1 displays $\mathrm{QO}_{2}$ and $\mathrm{CI}$ as a function of time for piglets in each experimental group. After $180 \mathrm{~min}$, both $\mathrm{QO}_{2}$ and $\mathrm{CI}$ were significantly reduced for piglets in group 1 (GBS) and group 2 (PE) compared to piglets receiving placebo (group 3). No differences in $\mathrm{QO}_{2}$ or $\mathrm{CI}$ were noted between groups 1 and 2 at any observation time. The reduction in $\mathrm{QO}_{2}$ noted in both groups 1 and 2 were accounted for entirely by a fall in CI. No significant changes were noted in $[\mathrm{Hb}]$ or $\mathrm{SataO}_{2}$ for piglets in either group 1 or 2 at any time during the experimental observation period (not shown).

Figure 2 displays $\mathrm{pH}$ and arterial $\mathrm{BD}$ as a function of time for piglets in each experimental group. At 120,150, and $180 \mathrm{~min}$, $\mathrm{pH}$ was significantly lower and at 150 and $180 \mathrm{~min}$ BD was significantly more negative for piglets receiving GBS (group 1) compared to piglets receiving either PE (group 2) or placebo (group 3). No differences in either $\mathrm{pH}$ or BD were noted between groups 2 and 3 at any observation time. The significant reduction in $\mathrm{pH}$ noted for piglets in group 1 was accounted for entirely by BD. No significant differences in $\mathrm{PaCO}_{2}$ were noted among the experimental groups.

Figure 3 displays $\mathrm{VO}_{2}$ and $\mathrm{Q}_{2}$ extraction ratio as a function of time for piglets in each experimental group. $\mathrm{VO}_{2}$ did not differ significantly among the three experimental groups at any observation time. Furthermore, determination of $\mathrm{VO}_{2}$ as a function of time within the single group of piglets receiving GBS (group 1) revealed no significant change in $\mathrm{VO}_{2}$ during the course of the experiment. At 150 and $180 \mathrm{~min}$ the $\mathrm{O}_{2}$ extraction ratio for pigets in group 1 (GBS) rose significantly compared to piglets in group 3 (placebo), but at no time did $\mathrm{O}_{2}$ extraction ratio differ comparing piglets in groups 1 (GBS) and 2 (PE). 

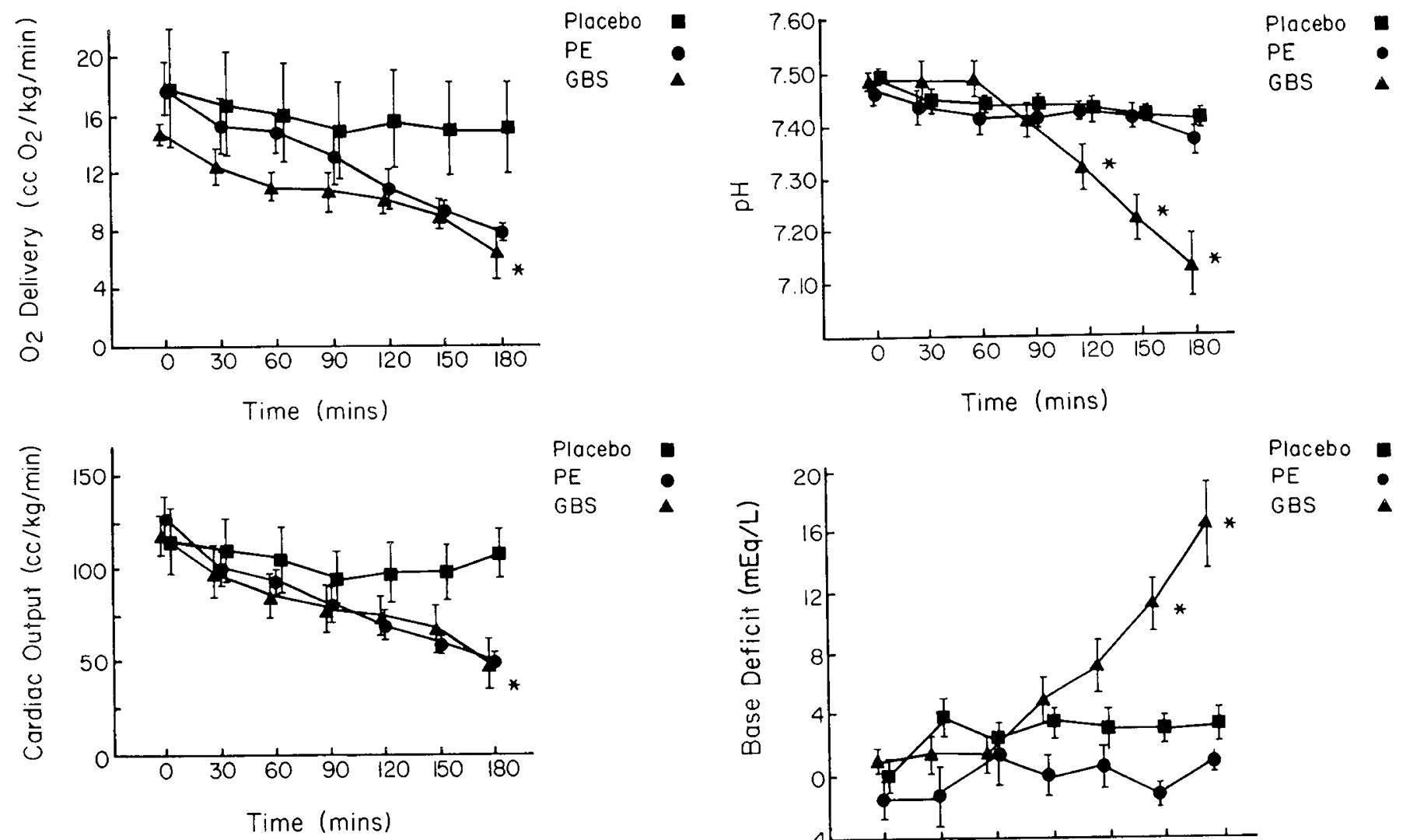

Fig. 1. $\mathrm{QO}_{2}(\mathrm{ml}$ oxygen $/ \mathrm{kg} / \mathrm{min})$ and $\mathrm{CO}(\mathrm{ml} \mathrm{blood} / \mathrm{kg} / \mathrm{min})$ expressed as a function of time for each experimental group. Data displayed as mean $\pm \mathrm{SE} ; n=$ six animals/group. Statistical significance $(p<0.05$ ANOVA, placebo versus GBS and PE) designated by asterisk.

Figure 4 displays AOP as a function of time for piglets in each experimental group. At 60,90 , and $120 \mathrm{~min}$ AOP was significantly greater for group 2 (PE) than either group 1 or 3 which did not differ from each other. At $180 \mathrm{~min}$, AOP was significantly lower for group 1 (GBS) than either group 2 or 3, which did not differ from each other. At 120,150, and $180 \mathrm{~min}$, SVRI was significantly higher for group 2 (PE) than either groups 1 or 3 which did not differ significantly from each other at any time (not shown).

\section{DISCUSSION}

Sepsis in adult humans is generally characterized by a hemodynamic state of "warm shock" in which CO is elevated, SVR is reduced, and metabolic acidosis develops despite normal or supernormal values of $\mathrm{QO}_{2}(14-16)$. In contrast, sepsis in neonates is generally characterized by "cold shock" in which $\mathrm{CO}$ is reduced, SVR is elevated, and metabolic acidosis develops in the context of subnormal $\mathrm{QO}_{2}(3,5,6,17-19)$.

The mechanism responsible for the fall in $\mathrm{CO}$ and $\mathrm{QO}_{2}$ during neonatal sepsis has not been well established in humans $(5,6)$, lambs (19), or piglets $(1,3,17,18)$. We have demonstrated previously that hypovolemia, although a common consequence of sepsis $(19,20)$, is not a hemodynamic prerequisite for reduction of $\mathrm{CO}$ or $\mathrm{QO}_{2}$ in septic piglets (1-4). Further, we have noted no elevation of CVP during GBS infusion in piglets, suggesting that right ventricular failure does not occur despite markedly elevated pulmonary artery pressures observed in septic piglets. Peevy et al. (22), and others $(21,23)$ have demonstrated the association of elevated levels of thromboxane with reduced $\mathrm{CO}$ during GBS sepsis, and have subsequently observed an improvement in cardiac function with prostaglandin synthetase inhibition. These observations are consistent with the hypothesis that hemodynamic consequences of GBS sepsis are mediated, at least in part, by circulating prostaglandins.

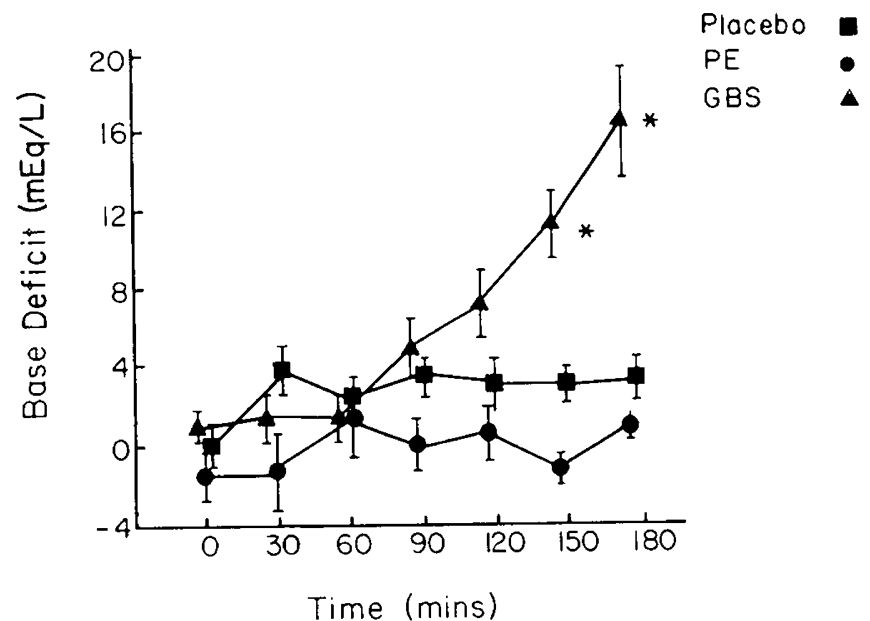

Fig. 2. $\mathrm{pH}(\mathrm{U})$ and base deficit ( $\mathrm{mEq} /$ liter) expressed as a function of time for each experimental group. Data displayed as mean \pm SE: $n=$ six animals/group. Statistical significance $(p<0.05$ ANOVA. GBS versus placebo and $\mathrm{PE}$ ) designated by asterisks.

The mechanism underlying the development of acidosis in neonatal sepsis, and its relationship to the low values of $\mathrm{QO}_{2}$ observed in septic newborns, has not been well established. We demonstrate here that equivalent reductions in systemic $\mathrm{CI}$ and $\mathrm{QO}_{2}$ (comparing GBS- and PE-treated piglets) resulted in a significant metabolic acidosis only for the septic animals. These results suggest that a reduction in systemic $\mathrm{QO}_{2}$ is not, in itself, sufficient to account for the development of metabolic acidosis in this piglet model of GBS sepsis. In addition, although both hypotension and hypoxemia may be present in acidotic human infants with GBS sepsis, neither hypotension (reduction of blood pressure below a "critical closing" value for the peripheral microcirculation) nor hypoxemia (reduction of systemic $\mathrm{QO}_{2}$ via arterial desaturation) contributed to the differential acidosis comparing septic vs PE- and placebo-treated piglets at 120 and 150 minutes in these protocols.

Our data are consistent with either of two mechanisms previously hypothesized to account for the development of metabolic acidosis in sepsis:

Hypothesis 1. Sepsis is associated with a disruption of lactate metabolism, either by increasing lactate production (for example, from amino acid catabolism) or by reducing lactate turnover (for example, via disrupting either the Krebs cycle or mitochondrial electron transport) $(14,16,24,25)$. According to this "metabolic poison" hypothesis, hemodynamic alterations need not be invoked to account for the development of acidosis in sepsis. This view is consistent with observations in adults with "warm" or high-output sepsis, where $\mathrm{QO}_{2}$ appears not to limit $\mathrm{VO}_{2}$, yet acidosis develops (18-20,27).

Hypothesis 2. Sepsis is associated with an elevation of the 


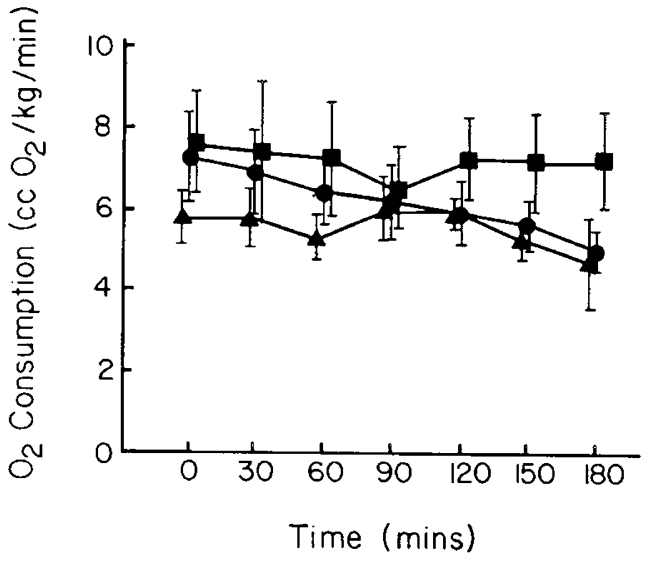

Placebo
PE
GBS

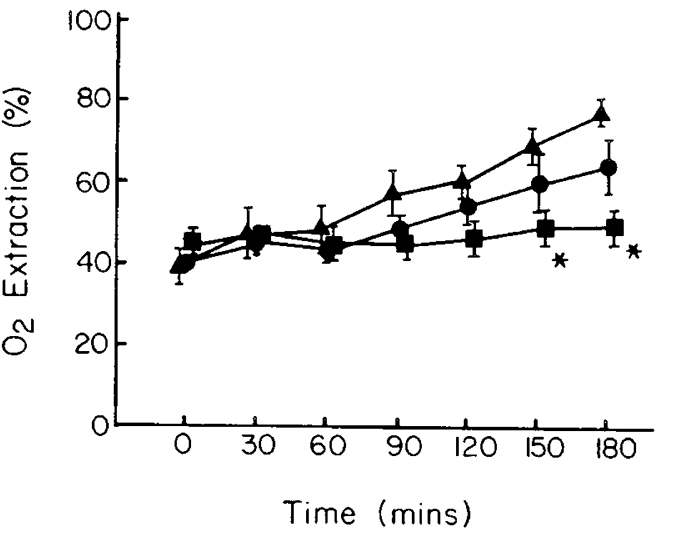

Placebo

PE

GBS

Fig. 3. $\mathrm{VO}_{2}(\mathrm{ml}$ oxygen $/ \mathrm{kg} / \mathrm{min})$ and oxygen extraction (\%) expressed as a function of time for each experimental group. Data displayed as mean $\pm \mathrm{SE} ; n=$ six animals/group. Statistical significance $(p<0.05$ ANOVA, placebo versus GBS) designated by asterisks.

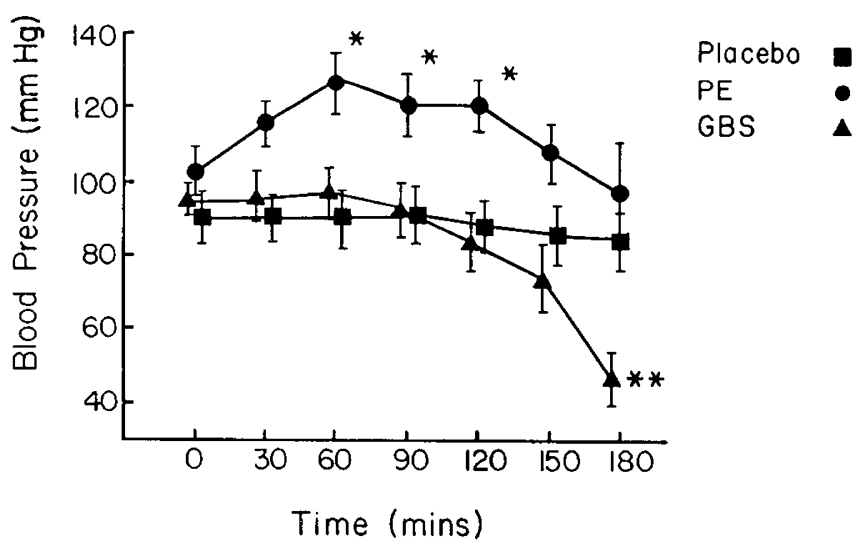

Fig. 4. Blood pressure expressed as a function of time for each experimental group. Data displayed as mean $\pm \mathrm{SE} ; n=$ six animals/group. Statistical significance ( $p<0.05$ ANOVA, PE versus GBS and placebo) designated by asterisks. Statistical significance $(p<0.05$ ANOVA, GBS versus $\mathrm{PE}$ and placebo) designated by double asterisk.

"critical $\mathrm{QO}_{2}$ "; i.e. sepsis increases the value of $\mathrm{QO}_{2}$ below which aerobic metabolism cannot be sustained (cf. 26). This hypothesis suggests that a level of $\mathrm{QO}_{2}$ which is adequate to support aerobic metabolism in nonseptic animals becomes inadequate during sepsis. This mechanism would account for the development of metabolic acidosis in piglets with GBS (group 1) at levels of $\mathrm{QO}_{2}$ which did not produce acidosis in nonseptic (group 2) animals. This view is compatible with results obtained by Nelson et al. (27) who utilized a model of stagnant hypoxia to demonstrate an increase in critical $\mathrm{QO}_{2}$ during Pseudomonas aeruginosa bacteremia in adult dogs.
In summary, our data suggest that a reduction in overall systemic $\mathrm{QO}_{2}$ is not sufficient to account for the development of acidosis in a "cold shock" model of GBS sepsis in piglets. To the extent that these observations can be extrapolated to septic human newborns, we suggest that therapeutic interventions directed solely at restoring systemic $\mathrm{QO}_{2}$ may not optimally improve sepsis-induced metabolic acidosis, even in high-vascularresistance, low-cardiac-output sepsis states. Additional investigations of the coupling of metabolism, $\mathrm{VO}_{2}$, and $\mathrm{QO}_{2}$ during sepsis will be needed before further insights into the cause, and potential cure, of sepsis-associated acidosis are gained.

\section{REFERENCES}

1. Meadow WL, Meus PJ 1984 Hemodynamic consequences of tolazoline infusion in neonatal group B streptococcal bacteremia: an animal model. Pediatr Res 18:960-965

2. Meadow WL, Meus PJ 1985 Unsuspected mesenteric hypoperfusion despite apparent hemodynamic recovery in the early phase of septic shock in piglets. Circ Shock 15:123-129

3. Meadow WL, Meus PJ 1986 Early and late consequences of group B beta streptococcal sepsis in piglets. Circ Shock 19:347-356

4. Meadow WL, Rudinsky BF, Strates E 1986 Selective elevation of systemic blood pressure by epinephrine during sepsis-induced pulmonary hypertension in piglets. Pediatr Res 20:872-875

5. Baker CJ 1979 Group B streptococcal infections in neonates. Pediatr Rev 1:515

6. Quirante J, Ceballos R, Cassady G 1974 Group B beta-hemolytic streptococcal infection in the newborn. Am $J$ Dis Child 128:659-665

7. Menke JA, Giacoia GP, Jolkin H 1979 Group B beta hemolytic streptococcal sepsis and the idiopathic respiratory distress syndrome: a comparison. J Pediatr 94:467-471

8. Siegel JD, McCracken GH 1981 Sepsis Neonatorum. N Engl J Med 304:642647

9. Katzenstein AL, Davis C, Braude A 1976 Pulmonary changes in neonatal sepsis due to group B beta-hemolytic streptococcus: relation to hyaline membrane disease. J Infect Dis 133:430-435

10. Drummond WH, Peckham GJ, Fox WW 1977 The clinical profile of the newborn with persistent pulmonary hypertension. Clin Pediatr 16:335-340

11. Weil M 1977 Current understanding of mechanisms and treatment of circulatory shock caused by bacterial infections. Ann Clin Res 9:181-191

12. Perkin RM, Levin DL 1982 Shock in the pediatric patients: part II. Therapy. J Pediatr 101:319-332

13. Glanz SA 1981 A Primer of Biostatistics. McGraw Hill, New York

14. Cerra FB, Siegel JH, Border JR, Peters DM, McMenamy RR 1979 Correlations between metabolic and cardiopulmonary measurements in patients after trauma, general surgery, and sepsis. J Trauma 19:621-629

15. Cowan BN, Burns HJG, Boyle P, Ledingham IM 1984 The relative prognostic value of lactate and hemodynamic measurements in early shock. Anaesthesia 39:750-755

16. Duff $J 1977$ Cardiovascular and metabolic changes in shock and sepsis. Eur Surg Res 9:155-165

17. Runkle B, Goldberg RN, Streitfeld MM, Clark MR, Buron E, Setzer ES, Bancalari E 1984 Cardiovascular changes in group B streptococcal sepsis in the piglet: response to indomethacin and relationship to prostacyclin and tromboxane A2. Pediatr Res 18:874-879

18. Goldberg RN, Suguihara C, Steitfeld MM, Runkle B, Bancalari E 1985 Effects of leukotriene antagonist FPL57231 on the early hemodynamic manifestations of group B Beta Streptococcal sepsis (GBS) in piglets. Pediatr Res 19:342A(abstr)

19. Rojas J, Green RS, Hellerquisht CG, Olegard R, Brigham KL, Stahlman MT 1981 Studies on group B beta-hemolytic streptococcus. II. Effects on pulmonary hemodynamics and vascular permeability in unanesthetized sheep. Pediatr Res 15:899-904

20. Hinshaw LB, Greenfield LJ, Owen SE, Black MR, Guenter Ca 1972 Precipitation of cardiac failure in endotoxin shock. Surg Gynecol Obstet 135:3948

21. Hammerman C, Meadow WL, Strates E. Wu H-S 1985 Selective inhibition of thromboxane synthetase reduces septic pulmonary hypertension in piglets. Pediatr Res 19:173a(abstr)

22. Peevy K, Chartrand S, Wiseman H, Boerth R, Olson R 1985 Myocardial dysfunction in group B streptococcal shock. Pediatr Res 19:511-513

23. Philips JB, Lyrene RK 1984 Prostaglandins, related compounds, and the perinatal pulmonary circulation. Clin Perinatol 11:565-579

24. Siegel JH, Greenspan M, Del Guercio LR 1967 Abnormal vascular tone, defective oxygen transport and myocardial failure in human septic shock. Ann Surg 165:504-517

25. Wright CJ, Duff JH, McClean APH, MacLean ED 1971 Regional capillary blood flow and oxygen uptake in severe sepsis. Surg Gynecol Obstet 130:637644

26. Danek SJ, Lynch JP, Weg JG, Dantzker DR 1980 The dependence of oxygen uptake on oxygen delivery in the adult respiratory distress syndrome. Am Rev Respir Dis 122:387-395

27. Nelson D, Schumacker PT, Wood LDH: Pathological supply dependence of oxygen uptake in bacteremic dogs. Am J Physiol (in press) 